\title{
An optical model for deriving the spectral particulate backscattering coefficients in oceanic waters
}

\author{
S. P. Tiwari and P. Shanmugam \\ Department of Ocean Engineering, Indian Institute of Technology Madras, Chennai-600036, India \\ Correspondence to: P. Shanmugam (pshanmugam@iitm.ac.in)
}

Received: 26 October 2012 - Published in Ocean Sci. Discuss.: 4 February 2013

Revised: 27 September 2013 - Accepted: 23 October 2013 - Published: 21 November 2013

\begin{abstract}
An optical model is developed based on the diffuse attenuation coefficient $\left(K_{\mathrm{d}}\right)$ to estimate particulate backscattering coefficients $b_{\mathrm{bp}}(\lambda)$ in oceanic waters. A large in situ data set is used to establish robust relationships between $b_{\mathrm{bp}}(530)$ and $b_{\mathrm{bp}}(555)$ and $K_{\mathrm{d}}(490)$ using an efficient nonlinear least-square method which uses the trust region algorithm with Bisquare weights scheme to adjust the coefficients. These relationships are obtained with good correlation coefficients $\left(R^{2}=0.786\right.$ and 0.790$)$, low root mean square error $(\mathrm{RMSE}=0.00076$ and 0.00072$)$ and $95 \%$ confidence bounds. The new model is tested with three independent data sets: the NOMAD SeaWiFS Match ups, OOXIX IOP algorithm workshop evaluation data set (Version 2.0w APLHA), and IOCCG simulated data set. Results show that the new model makes good retrievals of $b_{\mathrm{bp}}$ at all key wavelengths (from $412-683 \mathrm{~nm}$ ), with statistically significant improvements over other inversion models. Thus, the new model has the potential to improve our present knowledge of particulate matter and their optical variability in oceanic waters.
\end{abstract}

\section{Introduction}

Knowledge of light scattering and absorption properties of the seawater constituents is very important in understanding spectral reflectance and its variability (Gordon et al., 1975). Among these properties, spectral particulate backscattering $b_{\text {bp }}(\lambda)$ has scientific implications and practical applications in optical remote sensing, as the light backscattered from various seawater constituents provides the possibility to derive information on the particulate populations under investigation (Shanmugam et al., 2011). The particulate backscattering depends at first order on the particulate concentration, and at second order on the chemical composition (index of refraction), particle size distribution (PSD), and structure of the bulk particulate matter (Stramski et al., 2004). The recent field measurements showed that particles smaller than three microns contribute to about $50 \%$ of $b_{\mathrm{bp}}$, in contrast to the results based on the Mie scattering theory (Antoine et el., 2011; Dall'Olmo et al., 2009; Loisel et al., 2011; Morel and Ahn, 1991; Stramski and Kiefer, 1991). The fraction of $b_{\text {bp }}$ affects the ocean colour, determined by the relative contribution of living and nonliving particles (such as inorganic minerals, phytoplankton, and organic detritus) (Gordon et al., 1975). In open ocean waters, most of the scattering covaries with the phytoplankton concentration. However, in coastal waters the scattering property is determined by particles derived from the river advection, waves and currents, local biogenic production, and atmospheric deposition. These sources display significant spatial and temporal variations in the particulate populations, and therefore the corresponding variations in ocean colour. However, our present knowledge of these variations in scattering properties of the particulate load (e.g. suspended sediments, phytoplankton blooms, detritus, composition and size) (van de Hulst, 1981) in coastal waters under investigation remains poorly understood (Shanmugam et al., 2011).

Many empirical and semi-analytical algorithms have been developed in the recent decades (Gordon et al., 1988; Garver and Siegel, 1997; Carder et al., 1999; IOCCG, 2006) to estimate particulate backscattering coefficients from remotesensing data. The empirical algorithms are generally derived from the relationship of irradiance reflectance or remotesensing reflectance and backscattering coefficients, and are often used for estimating $b_{\mathrm{bp}}(\lambda)$ in clear ocean waters. However, these algorithms produce large errors in coastal waters 
(with high mineral particle concentrations). The Mie theory implementation is also limited by the lack of knowledge on the imaginary part of refractive index and assumption of the same particle size distribution for organic and inorganic fractions of seawater (Stramski et al., 2001; Twardowski et al., 2001; Risovic, 2002; Babin et al., 2003; Green et al., 2003). Semi-analytical models are based on radiative transfer theory (Maritorena et al., 2002), and can be applied to a wide range of the ocean environments. Recently, commercial instruments (e.g. AC-S, BB9 (WET Labs Inc.)) have become available for direct measurements of scattering and backscattering properties (Twardowski et al., 2005, 2009). Unfortunately, practical difficulties are associated with these instruments for direct measurements of the volume scattering function (VSF) at sufficient angular and spectral ranges (Chami et al., 2006).

The objectives of this work are to develop a robust model to estimate spectral particulate backscattering coefficients in oceanic waters, to evaluate its performance using independent in situ data and SeaWiFS satellite match ups from a variety of waters, and to compare its results with those of the global inversion models (IOCCG, 2006).

\section{Data and method}

\subsection{In situ data}

The NASA bio-Optical Marine Algorithm Dataset (NOMAD) - a global, high-quality in situ data highly suitable for algorithm development and validation (Werdell and Bailey, 2005) was obtained from the NASA SeaWiFS Biooptical Archive and Storage System (SeaBASS). This data set contains coincident measurements of $b_{\mathrm{b}}, \mathrm{Chl}, R_{\mathrm{rs}}(\lambda)$, $K_{\mathrm{d}}$ and other data collected simultaneously in various regional and global waters. It also contains concurrent SeaWiFS remote-sensing reflectances $\left(R_{\mathrm{rs}}\right)$ and in situ $b_{\mathrm{b}}$ at several key wavelengths. A subset of NOMAD in situ data was made of co-located $b_{\mathrm{b}}$ (for several wavelengths between 405 and $683 \mathrm{~nm}$ ) and corresponding remote-sensing reflectances ( $N=331$, hereafter referred as NOMAD-A). The satellite match ups consisted of 125 valid data points for both $b_{\mathrm{b}}$ and $R_{\mathrm{rs}}$ at the SeaWiFS wavebands. This independent validation data set is hereafter referred to as NOMAD-B.

The NASA NOMAD OOXIX IOP algorithm workshop evaluation data (Version 2.0w APLHA) were used as independent data sets (after eliminating certain data common to NOMAD-A) for validating the new model in the context of remote-sensing applications (Werdell and Bailey, 2005; Werdell, 2009; Brewin et al., 2011). The later data set consisted of 185 matched remote-sensing reflectances at SeaWiFS wavebands and in situ particulate backscattering coefficients (hereafter referred as NOMAD-C data). Note that a few of these measurements were not independent of the NOMAD-A samples used in NOMAD-C data sets (most of the overlapping data sets removed to assess the validity of the models). For the NOMAD data set, the particulate backscattering $b_{\mathrm{bp}}(\lambda)$ values were obtained according to $b_{\mathrm{bp}}(\lambda)=b_{\mathrm{b}}(\lambda)-b_{\mathrm{bw}}(\lambda)$, where $b_{\mathrm{bw}}(\lambda)$ is the backscattering coefficient of pure seawater obtained from Smith and Baker (1981).

The IOCCG simulated data set (for the sun at $30^{\circ}$ from the zenith; considered $N=500$ ) previously used by the IOCCG working group (for IOPs) for validation of several inversion models (IOCCG, 2006) was also used in the present investigation.

Figure 1 shows the histograms of four data sets (in situ and IOCCG simulated) of $b_{\mathrm{bp}}(\lambda)$ at 530 and $555 \mathrm{~nm}$ and corresponding $R_{\mathrm{rs}}$ at 490 and $555 \mathrm{~nm}$ for a wide range of waters. The low-high values of the histograms correspond to clear waters to coastal waters.

\section{Model description}

\subsection{Particulate backscattering coefficient - background}

The backscattering coefficient $\left(b_{\mathrm{b}}\right)$ is an inherent optical property (IOP) (Preisendorfer, 1961) which is defined as a function of the volume scattering function (VSF), $\beta(\lambda, \theta)$. It describes the scattered radiant intensity into a scattering angle $\theta$ per unit irradiance of the incident unpolarized beam of the light per unit volume of water (Mobley, 1994 and 1995). The integration of $\beta(\lambda, \theta)$ (VSF with units $\mathrm{m}^{-1} \mathrm{sr}^{-1}$ where $\theta$ is the scattering angle and $\lambda$ the wavelength) over the backward hemisphere provides the backscattering coefficient through the following expression:

$b_{\mathrm{b}}(\lambda)=2 \pi \int_{\pi / 2}^{\pi} \beta(\lambda, \theta) \sin (\lambda) d \theta$.

This approach is not often used because it requires detailed scattering information over a wide range, and the instrumentation is not yet commercially available to carry out such measurements in the ocean environment. The combination of randomly oriented molecules, marine inorganic and organic (living or nonliving) particles, and bubbles in seawater contributes to $b_{\mathrm{b}}$. However, determination of how the relative contributions of these components vary as a function of the physical and bio-optical state of oceanic waters remains an elusive task (Stramski et al., 2004).

The total backscattering coefficient $b_{\mathrm{b}}(\lambda)$ is the sum of the backscattering by pure water $b_{\mathrm{bw}}(\lambda)$ and particulate backscattering $b_{\mathrm{bp}}(\lambda)$.

$b_{\mathrm{b}}(\lambda)=b_{\mathrm{bw}}(\lambda)+b_{\mathrm{bp}}(\lambda)$

Hence, backscattering by particles $b_{\text {bp }}$ can be described as follows:

$b_{\mathrm{bp}}(\lambda)=b_{\mathrm{b}}(\lambda)-b_{\mathrm{bw}}(\lambda)$, 

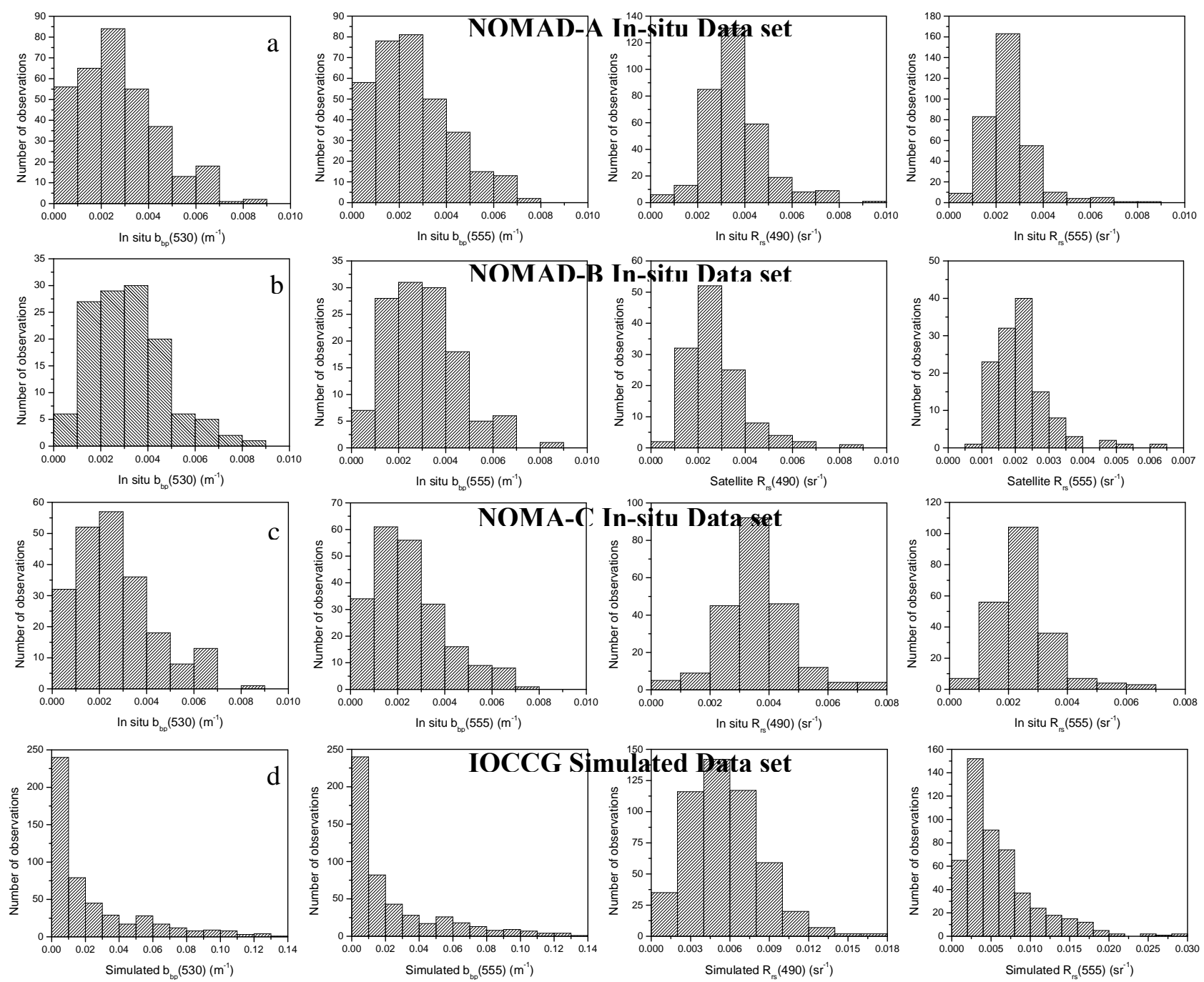

Fig. 1. Histogram of the particulate backscattering $\left(b_{\mathrm{bp}}\right)$ coefficients at 530 and $555 \mathrm{~nm}$ and the remote-sensing reflectance at 490 and $555 \mathrm{~nm}$ from four data sets. (a) NOMAD-A $(N=331)$, (b) NOMAD-B $(N=125)$, (c) NOMAD-C $(N=217)$, and (d) IOCCG simulated data set $(N=500)$.

where the scattering coefficient of pure seawater $\left(b_{\mathrm{w}}\right)$ is obtained from Smith and Baker (1981) to derive the backscattering by pure seawater $\left(b_{\mathrm{bw}}=b_{\mathrm{w}} / 2\right)$.

In the recent decades, many laboratory and field investigations yielded robust constraints on the absorption basis function spectral variations (Roesler et. al., 2003). Since backscattering sensors are relatively new, there is less information on backscattering basis functions. Previous studies by Morel and Ahn (1991) and Stramski and Kiefer (1991) demonstrated that most of the backscattering $(70-90 \%)$ in ocean waters is caused by particles smaller than $1 \mu \mathrm{m}$. In fact, the Mie theory was used to compute optical properties of particles (for absorbing spheres) which yielded strong spectral features near the absorption peaks (van de Hulst, 1957; Gordon, 1974; Bricaud and Morel, 1986; Zaneveld and Kitchen, 1995). However, there was difficulty in constraining these features which led to the implementation of the Mie theory for populations of non-absorbing homogeneous spheres, in which $b_{\text {bp }}$ was expressed as a smoothly varying function (Morel, 1973). Thus, the particulate backscattering $b_{\mathrm{bp}}(\lambda)$ can be defined as

$b_{\mathrm{bp}}(\lambda)=b_{\mathrm{bp}}\left(\lambda_{\mathrm{r}}\right) \times\left(\frac{555}{\lambda}\right)^{Y}$,

where $b_{\mathrm{bp}}(\lambda)$ and $b_{\mathrm{bp}}\left(\lambda_{\mathrm{r}}\right)$ are the particulate backscattering coefficient at a desired wavelength and a reference wavelength, respectively. $Y$ is the spectral slope that determines variability, shape, and magnitude of the particulate backscattering spectra. Most of the inversion models use Eq. (4) with slight modification for retrieval of the particulate backscattering coefficients from satellite ocean colour data. 


\subsection{Modelling particulate backscattering coefficient}

For deriving the particulate backscattering coefficients, some studies showed good correlation between $b_{\mathrm{bp}}$ and $R_{\mathrm{rs}}$ and others found better correlations between $b_{\mathrm{bp}}$ and chlorophyll (Chl) or suspended sediment (SS) concentration (Boss et al., 2009; Sun et al., 2009; Victor et al., 2010). It should be noted that these relationships are not always consistent due to the lack of a theoretical framework for predicting $b_{\mathrm{bp}}$. Our present understanding of major contributions to $b_{\mathrm{bp}}$ in natural waters is therefore uncertain, and it is unknown which particles backscatter light most efficiently (Stramski et al., 2004). Mie calculations (for scattering) suggest that significant contributions to $b_{\mathrm{bp}}$ come from submicron particles (Stramski and Kiefer, 1991), but there is evidence that application of this theory is inadequate for computation of $b_{\mathrm{bp}}$ for particle assemblages in natural waters (Bohren and Singham, 1991; Kitchen and Zenveld, 1992; Clavano et al., 2007). Thus, the current inversion models are limited to relatively clear ocean waters because of their difficulty in determining $b_{\mathrm{bp}}$ features (i.e. spectral signature and magnitude) in turbid coastal waters (Shanmugam et al., 2011). This prevents our knowledge of $b_{\mathrm{bp}}$ and thus interpretation of ocean colour signals (Antoine et al., 2011). In order to obtain more accurate $b_{\mathrm{bp}}$ values, new models with better parameterizations are needed to derive $b_{\mathrm{bp}}$ features over the entire visible wavelength domain.

The spectral diffuse attenuation coefficient $K_{\mathrm{d}}(\lambda)$ is one of the most important apparent optical properties (AOPs) (Preisendorfer, 1976) of seawater, directly linked to IOPs such as absorption and backscattering properties (Sathyendranath and Platt, 1988; Gordon, 1989; Lee et al., 2005a and b). Several studies were already conducted on $K_{\mathrm{d}}(\lambda)$ in different waters (Kirk, 1981, 1984, 1991; Morel and Loisel, 1998; Lee et al., 2005a and b).

This optical property is indicative of how strongly light at a particular wavelength is attenuated within the water column, thus it has wide applicability in ocean optics and remotesensing applications. It plays a very critical role to understand backscattering and absorption properties, photosynthesis and primary productivity models (Platt, 1986; Sathyendranath, 1989), heat budgets (Lewis, 1990; Morel, 1994), other biological processes in the water column, and to classify water types (Jerlov, 1976).

The relationships between the diffuse attenuation coefficient and particulate backscattering can be understood by studying the underwater light. The propagation of downwelling irradiance at particular wavelength $(\lambda)$ from the surface to a particular depth $(z)$ in the water column is known as diffuse attenuation coefficient. $K_{\mathrm{d}}$ values show an increasing dependency on solar zenith angle and absorption from blue to the red wavelengths. In principle, $K_{\mathrm{d}}$ represents a cumulative decrease in the downwelling irradiance along the depth and generally should be proportional to the path length of photons in the water. It is known that an inverse relationship between the $K_{\mathrm{d}}$ and average cosine an- gle is expected for a purely absorptive water body. However, in natural water bodies, scattering by water molecules and particulate matters tends to cause the underwater light field geometry to be more isotropic radiance distribution. Therefore, $K_{\mathrm{d}}$ is weakly dependent on the solar zenith angle at the wavelengths $<510 \mathrm{~nm}$ than at the red wavelengths, and the backscattering effect is dominant over the absorption (Zheng et al., 2002). Therefore, a proportionality of $K_{\mathrm{d}}$ and $b_{\mathrm{bp}}$ can be correlated on the above underwater light conditions. Since the present study focuses on the surface water backscattering properties, it is clear that the dependency of $K_{\mathrm{d}}$ at $490 \mathrm{~nm}$ on solar zenith angle is nearly negligible or a very weak function while the influence of backscattering on $K_{\mathrm{d}}$ at the short wavelengths is dominant.

The nonlinear least-square method is better suited to fit a nonlinear model to data. This type of model is defined by an equation that is nonlinear in the coefficients or a combination of linear and nonlinear in the coefficients. Mathematically, the nonlinear model is given by the formula $z=f(\chi, \gamma)+\varepsilon$, where $\mathrm{z}$ is the response, and can be derived using a set of coefficients $(\gamma)$ and variable quantity $(\chi)$ with an approximate error value $(\varepsilon)$. Linear models are easy to solve using the simple mathematical regression analysis, while nonlinear models are more difficult to fit; thus, an iterative method is used to determine the required coefficients to obtain the desired response including the approximate error value. The fitted response value $z^{\wedge}=f(\chi, p)$ is produced after the successive iterative process to produce a new set of coefficients $(p)$ and reduce residuals between the data and the fitted curve, until the fit reaches the specified convergence criteria, which involves the calculation of the Jacobian of $f(\chi, p)$, which is defined as a matrix of partial derivatives taken with respect to the coefficients.

In this study, a suitable $K_{\mathrm{d}}$-based model is developed to derive $b_{\mathrm{bp}}(\lambda)$ in the entire visible wavelength (400 to $700 \mathrm{~nm}$ ) domain. To estimate slope values and $b_{\mathrm{bp}}$ at a reference wavelength, the relationships of $K_{\mathrm{d}}(490)$ computed from updated Mueller (2000) algorithm (http://oceancolor. gsfc.nasa.gov/REPROCESSING/R2009/kdv4/) versus $b_{\text {bp }}$ (530) and (555) are obtained using the NOMAD-A biooptical data set. The power function is fitted to this in situ data using the non-linear least-square method, with good correlation coefficients $\left(R^{2}=0.786\right.$ for $b_{\mathrm{bp}}(530)$ versus $K_{\mathrm{d}}$ (490) and $R^{2}=0.790$ for $b_{\mathrm{bp}}(555)$ versus $\left.K_{\mathrm{d}}(490)\right)$, very small RMSE values ( 0.00076 and 0.00072 , respectively), and $95 \%$ confidence bounds (Fig. 2). The best-fit power equations coefficients are achieved using the trust region method along with Bisquare weights scheme to adjust the coefficients for a better fit, as it can solve difficult nonlinear problems more efficiently than the other methods (Coleman et al., 1996). The Bisquare weights scheme is used because it is very useful in minimizing the effect of outliers. The Mueller (2000) model is then used to estimate $K_{\mathrm{d}}$ at $490 \mathrm{~nm}$. 

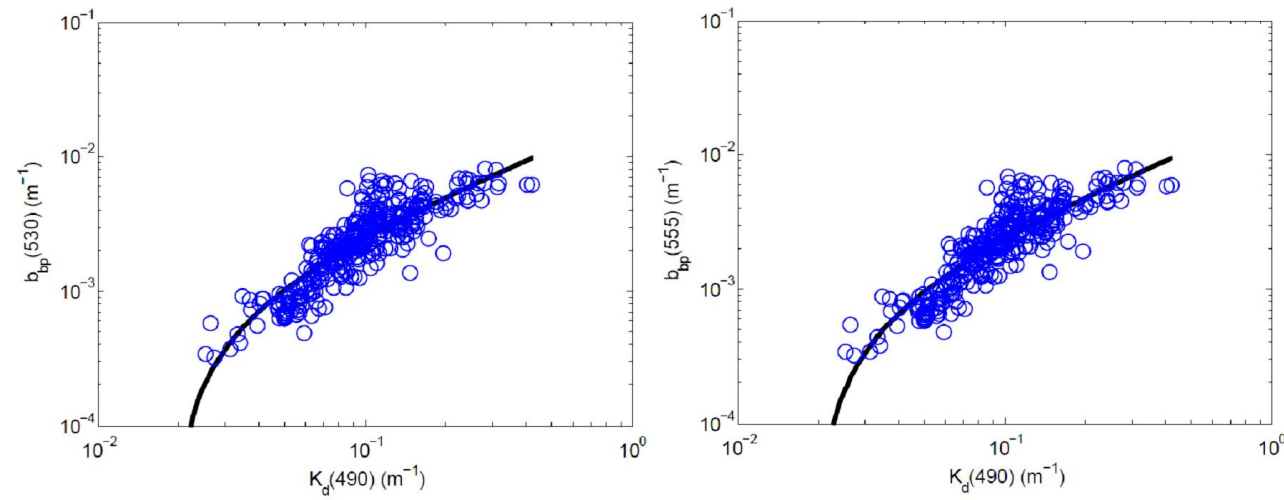

Fig. 2. Relationships between the $b_{\mathrm{bp}}(530)$ and $b_{\mathrm{bp}}(555)$ and diffuse attenuation coefficient $K_{\mathrm{d}}(490)$ from the NOMAD-A in situ data set $(N=331)$.

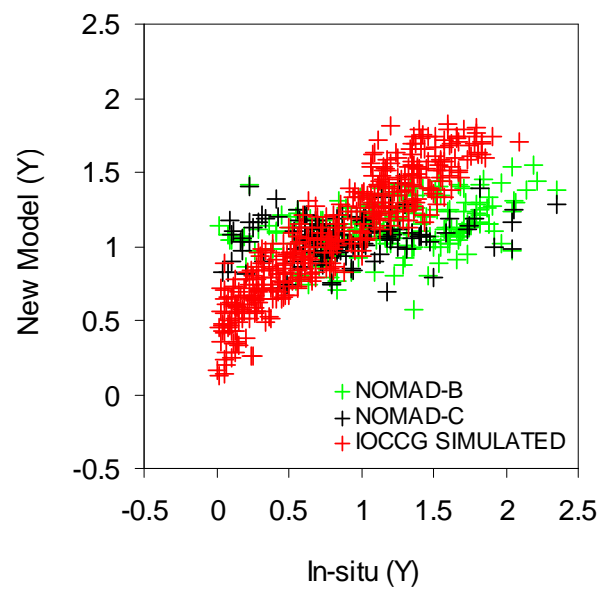

Fig. 3. Comparison of the calculated slope values $(Y)$ with those derived from the NOMAD in situ data and IOCCG simulated Data.

Consequently, the following equations are obtained:

$K_{\mathrm{d}}(490)=10^{\left(-0.8515-1.8263 X+1.8714 X^{2}-2.4414 X^{3}-1.0690 X^{4}\right)}+0.0166$

with $X=\log _{10}\left[R_{\mathrm{rs}}(490) / R_{\mathrm{rS}}(555)\right]$ (2009 Version).

$\begin{aligned} b_{\mathrm{bp}}(530) & =-0.0001618+0.0309 \times\left(K_{\mathrm{d}}(490)\right)^{1.095} \\ R^{2} & =0.786\end{aligned}$

$\begin{aligned} b_{\mathrm{bp}}(555) & =-0.0001568+0.0304 \times\left(K_{\mathrm{d}}(490)\right)^{1.109} ; \\ R^{2} & =0.790\end{aligned}$

The values of $Y$ are derived from the above Eqs. (6) and (7) of the $b_{\mathrm{bp}}(530)$ and $b_{\mathrm{bp}}$ (555) as follows:

Slope $Y=\frac{\log _{10}\left[b_{\mathrm{bp}}(530) / b_{\mathrm{bp}}(555)\right]}{\log _{10}[555 / 530]}$.

The derived $Y$ values vary from $0.574-1.55$ (average 1.126) for the NOMAD-B in situ data, 0.695-1.428 (average 1.053) for the NOMAD-C in situ data, and $0.128-1.822$ (average 1.0789; after eliminating few negative slope values encountered with this data) for the IOCCG simulated data. These calculated $Y$ values are also compared with the in situ $Y$ values from the above data sets (Fig. 3). No comparison was made with other models because they use constant slope values or their slopes are restricted to a narrow range. The calculated values of $b_{\mathrm{bp}}$ at the reference wavelength of $555 \mathrm{~nm}$ and $Y$ values from Eqs. (7) and (8) can be substituted in Eq. (4) to estimate $b_{\mathrm{bp}}(\lambda)$ coefficients in the entire visible wavelength domain. Indeed while $b_{\mathrm{bp}}$ can be relatively well estimated at each wavelength, the slight bias or errors on the estimated value of $b_{\mathrm{bp}}$ at each wavelength may have strong consequences on the $b_{\mathrm{bp}}$ slope estimated value, which can be used to assess the particle size distribution (Loisel et al., 2006; Kostadinov et al., 2009).

\section{Performance assessment}

The accuracy of the model is assessed by comparing its predicted $b_{\mathrm{bp}}(\lambda)$ values with in situ $b_{\mathrm{bp}}(\lambda)$ data. Two basic statistical measures are used such as the root mean square error (RMSE) and mean relative error (MRE). The accuracy of $b_{\mathrm{bp}}$ $(\lambda)$ predictions is also assessed based on the slope (S), intercept (I), and correlation coefficient $\left(R^{2}\right)$ of the linear regression between the in situ and predicted $b_{\mathrm{bp}}(\lambda)$ values. Systematic and random errors are calculated by the MRE and RMSE, respectively (IOCCG, 2006); these metrics are defined as

$\operatorname{RMSE}=\left(\frac{\sum_{i=1}^{\mathrm{N}}\left[\log \left(b_{\mathrm{bp} i}^{\text {model }}\right)-\log \left(b_{\mathrm{bp} i}^{\text {in situ }}\right)\right]^{2}}{N-2}\right)^{1 / 2}$

$\mathrm{MRE}=\sum_{i=1}^{N} \frac{\log \left(b_{\mathrm{bp} i}^{\text {model }}\right)-\log \left(b_{\mathrm{bp} i}^{\text {in situ }}\right)}{\log \left(b_{\mathrm{bp} i}^{\text {in situ }}\right)} \times 100 \%$, 
Table 1. Statistical comparisons between the modelled and known particulate backscattering (NOMAD-A in situ data). RMSE, MRE, BIAS and linear-regression results for the SeaWiFS bands centred at 412, 443, 490, 510, 530, 555, 670, and $683 \mathrm{~nm}$.

\begin{tabular}{lcrrrrrr}
\hline IOP & RMSE & MRE (\%) & BIAS & Slope & Intercept & $R^{2}$ & $\mathrm{~N}$ \\
\hline \multicolumn{7}{c}{ NOMAD-A } \\
\hline$b_{\text {bp }}(412)$ & 0.156 & 0.450 & 0.011 & 0.66 & -0.85 & 0.71 & 331 \\
$b_{\text {bp }}(443)$ & 0.149 & 0.370 & 0.010 & 0.69 & -0.80 & 0.74 & 331 \\
$b_{\text {bp }}(490)$ & 0.141 & 0.230 & 0.006 & 0.72 & -0.74 & 0.77 & 331 \\
$b_{\text {bp }}(510)$ & 0.139 & 0.170 & 0.005 & 0.73 & -0.72 & 0.78 & 331 \\
$b_{\text {bp }}(530)$ & 0.137 & 0.110 & 0.003 & 0.73 & -0.70 & 0.79 & 331 \\
$b_{\text {bp }}(555)$ & 0.135 & 0.040 & 0.001 & 0.74 & -0.69 & 0.80 & 331 \\
$b_{\text {bp }}(670)$ & 0.137 & -0.290 & -0.008 & 0.76 & -0.67 & 0.81 & 331 \\
$b_{\text {bp }}(683)$ & 0.138 & -0.330 & -0.009 & 0.76 & -0.68 & 0.81 & 331 \\
Average & 0.141 & 0.094 & 0.002 & 0.72 & -0.73 & 0.77 & 331 \\
\hline
\end{tabular}

Table 2. Statistical comparisons between the modelled (predicted by using the satellite SeaWiFS remote-sensing reflectance) and NOMADB in situ data. RMSE, MRE, BIAS and linear-regression results for the SeaWiFS bands centred at 412, 443, 490, 510, and 555 nm. It is expected that more errors are with abnormally/erroneously high $b_{\mathrm{bp}}(\lambda)$ values produced by the LM model.

\begin{tabular}{lcrccccc}
\hline IOP & RMSE & MRE $(\%)$ & BIAS & Slope & Intercept & $R^{2}$ & N \\
\hline & & & NM & & & & \\
\hline$b_{\text {bp }}(412)$ & 0.192 & 1.300 & 0.032 & 0.50 & -1.19 & 0.38 & 125 \\
$b_{\text {bp }}(443)$ & 0.189 & 1.120 & 0.028 & 0.53 & -1.15 & 0.41 & 125 \\
$b_{\text {bp }}(490)$ & 0.186 & 0.710 & 0.018 & 0.56 & -1.10 & 0.43 & 125 \\
$b_{\text {bp }}(510)$ & 0.185 & 0.620 & 0.016 & 0.57 & -1.09 & 0.44 & 125 \\
$b_{\text {bp }}(555)$ & 0.186 & 0.330 & 0.009 & 0.58 & -1.07 & 0.45 & 125 \\
Average & 0.188 & 0.816 & 0.020 & 0.55 & -1.12 & 0.42 & 125 \\
\hline & & & LM & & & & \\
\hline$b_{\text {bp }}(412)$ & 0.411 & -11.940 & -0.335 & 0.94 & -0.49 & 0.52 & 125 \\
$b_{\text {bp }}(443)$ & 0.418 & -11.990 & -0.341 & 0.93 & -0.53 & 0.51 & 125 \\
$b_{\text {bp }}(490)$ & 0.431 & -12.180 & -0.352 & 0.90 & -0.60 & 0.48 & 125 \\
$b_{\text {bp }}(510)$ & 0.435 & -12.170 & -0.354 & 0.89 & -0.64 & 0.47 & 125 \\
$b_{\text {bp }}(555)$ & 0.445 & -12.230 & -0.360 & 0.85 & -0.73 & 0.44 & 125 \\
Average & 0.428 & -12.102 & -0.348 & 0.90 & -0.60 & 0.48 & 125 \\
\hline & & & QAA & & & & \\
\hline$b_{\text {bp }}(412)$ & 0.383 & -8.310 & -0.224 & 0.21 & -2.18 & 0.04 & 125 \\
$b_{\text {bp }}(443)$ & 0.309 & -6.190 & -0.165 & 0.30 & -1.92 & 0.11 & 125 \\
$b_{\text {bp }}(490)$ & 0.225 & -3.310 & -0.087 & 0.42 & -1.56 & 0.29 & 125 \\
$b_{\text {bp }}(510)$ & 0.202 & -2.080 & -0.054 & 0.46 & -1.42 & 0.36 & 125 \\
$b_{\text {bp }}(555)$ & 0.188 & 0.480 & 0.012 & 0.55 & -1.14 & 0.43 & 125 \\
Average & 0.261 & -3.882 & -0.10 & 0.39 & -1.65 & 0.25 & 125 \\
\hline & & & GSM & & & & \\
\hline$b_{\text {bp }}(412)$ & 0.396 & -10.920 & -0.302 & 0.72 & -1.00 & 0.32 & 125 \\
$b_{\text {bp }}(443)$ & 0.349 & -8.790 & -0.240 & 0.72 & -0.94 & 0.33 & 125 \\
$b_{\text {bp }}(490)$ & 0.297 & -5.890 & -0.159 & 0.72 & -0.87 & 0.33 & 125 \\
$b_{\text {bp }}(510)$ & 0.280 & -4.660 & -0.124 & 0.72 & -0.85 & 0.33 & 125 \\
$b_{\text {bp }}(555)$ & 0.258 & -2.080 & -0.055 & 0.70 & -0.82 & 0.33 & 125 \\
Average & 0.316 & -6.468 & -0.176 & 0.71 & -0.90 & 0.33 & 125 \\
\hline & & & & & &
\end{tabular}


Table 3. Statistical comparisons between the modelled and NOMAD-C in situ data. RMSE, MRE, BIAS and linear-regression results for the SeaWiFS bands centred at 412, 443, 490, 510, and $555 \mathrm{~nm}$.

\begin{tabular}{lcrrrrrr}
\hline IOP & RMSE & MRE $(\%)$ & BIAS & Slope & Intercept & $R^{2}$ & N \\
\hline & \multicolumn{7}{c}{ NM } \\
\hline$b_{\text {bp }}(412)$ & 0.129 & -0.005 & -0.012 & 0.74 & -0.66 & 0.70 & 185 \\
$b_{\text {bp }}(443)$ & 0.125 & -0.003 & -0.007 & 0.76 & -0.61 & 0.73 & 185 \\
$b_{\text {bp }}(490)$ & 0.121 & -0.002 & -0.004 & 0.78 & -0.57 & 0.75 & 185 \\
$b_{\text {bp }}(510)$ & 0.121 & -0.001 & -0.001 & 0.78 & -0.57 & 0.76 & 185 \\
$b_{\text {bp }}(555)$ & 0.122 & 0.001 & 0.002 & 0.79 & -0.56 & 0.77 & 185 \\
Average & 0.124 & -0.002 & -0.004 & 0.77 & -0.60 & 0.74 & 185 \\
\hline & & & LM & & & & \\
\hline$b_{\text {bp }}(412)$ & 0.335 & -8.770 & -0.239 & 1.34 & 0.60 & 0.67 & 185 \\
$b_{\text {bp }}(443)$ & 0.327 & -8.510 & -0.234 & 1.35 & 0.64 & 0.70 & 185 \\
$b_{\text {bp }}(490)$ & 0.319 & -8.250 & -0.231 & 1.34 & 0.65 & 0.72 & 185 \\
$b_{\text {bp }}(510)$ & 0.315 & -8.070 & -0.228 & 1.33 & 0.64 & 0.73 & 185 \\
$b_{\text {bp }}(555)$ & 0.308 & -7.780 & -0.223 & 1.31 & 0.60 & 0.74 & 185 \\
Average & 0.321 & -8.276 & -0.231 & 1.33 & 0.63 & 0.71 & 185 \\
\hline & & & QAA & & & & \\
\hline & & & & & & \\
\hline$b_{\text {bp }}(412)$ & 0.213 & -2.210 & -0.056 & 0.32 & -1.74 & 0.25 & 185 \\
$b_{\text {bp }}(443)$ & 0.188 & -0.560 & -0.014 & 0.42 & -1.49 & 0.38 & 185 \\
$b_{\text {bp }}(490)$ & 0.169 & 1.580 & 0.040 & 0.54 & -1.14 & 0.55 & 185 \\
$b_{\text {bp }}(510)$ & 0.168 & 2.490 & 0.063 & 0.59 & -1.01 & 0.60 & 185 \\
$b_{\text {bp }}(555)$ & 0.179 & 4.320 & 0.109 & 0.68 & -0.74 & 0.69 & 185 \\
Average & 0.183 & 1.124 & 0.028 & 0.51 & -1.22 & 0.49 & 185 \\
\hline & & & GSM & & & & \\
\hline$b_{\text {bp }}(412)$ & 0.226 & -6.310 & -0.167 & 1.01 & -0.15 & 0.71 & 185 \\
$b_{\text {bp }}(443)$ & 0.173 & -3.630 & -0.095 & 1.01 & -0.07 & 0.74 & 185 \\
$b_{\text {bp }}(490)$ & 0.136 & 0.050 & 0.001 & 1.00 & 0.00 & 0.76 & 185 \\
$b_{\text {bp }}(510)$ & 0.141 & 1.610 & 0.041 & 0.99 & 0.03 & 0.77 & 185 \\
$b_{\text {bp }}(555)$ & 0.181 & 4.880 & 0.123 & 0.97 & 0.05 & 0.78 & 185 \\
Average & 0.171 & -0.680 & -0.019 & 1.00 & -0.03 & 0.75 & 185 \\
\hline & & & & & & & \\
\hline
\end{tabular}

where $b_{\mathrm{bp} i}^{\text {model }}$ stands for the model derived values, $b_{\mathrm{bp} i}^{\text {in } i \text { tu }}$ stands for the in situ measurements, and $\mathrm{N}$ is the number of valid retrievals. Tables 1, 2 and 3 summarise the statistical analyses results of the model validation with known $b_{\mathrm{bp}}(\lambda)$ data.

\section{Results}

The performance of the new model for predicting $b_{\mathrm{bp}}(\lambda)$ values was evaluated with three data sets: NOMAD-A data (used for the model parameterization at two wavelengths 530 and $555 \mathrm{~nm}$ ) at the wavelengths $412-683 \mathrm{~nm}$, independent NOMAD-B data (SeaWiFS satellite match ups) at the wavelengths $412-555 \mathrm{~nm}$, and NOMAD-C data at the wavelengths $412-555 \mathrm{~nm}$. The results of the new model are also compared with those of the other inversion models (e.g. LM, QAA, and GSM semi-analytical models). Further validation with IOCCG simulated data set was also performed. The sta- tistical evaluation results of these models are summarised in Tables 1, 2, 3, and 4. To gain further insight into their performances, scatter plots of the model $b_{\mathrm{bp}}(\lambda)$ values versus in situ $b_{\mathrm{bp}}(\lambda)$ values are shown at the key wavelengths in Fig. 5 and Figs. 8-10.

\subsection{Spectral variability of the particulate backscattering coefficient}

A large set of the particulate backscattering spectra was generated by the present model, with the varying spectral slope values that influence on the shape and magnitude of spectral $b_{\mathrm{bp}}(\lambda)$ curves, and compared with the corresponding in situ spectra (NOMAD-A) at the selected wavelengths (Fig. 4). The spectral comparison is interesting as the shape and magnitude of the modelled spectral $b_{\mathrm{bp}}(\lambda)$ curves are consistent with those of the in situ spectral $b_{\mathrm{bp}}(\lambda)$ curves. It is observed that the $b_{\mathrm{bp}}$ values are strong in the blue (e.g. 412 and $443 \mathrm{~nm}$ ) domain and decrease towards the longer 

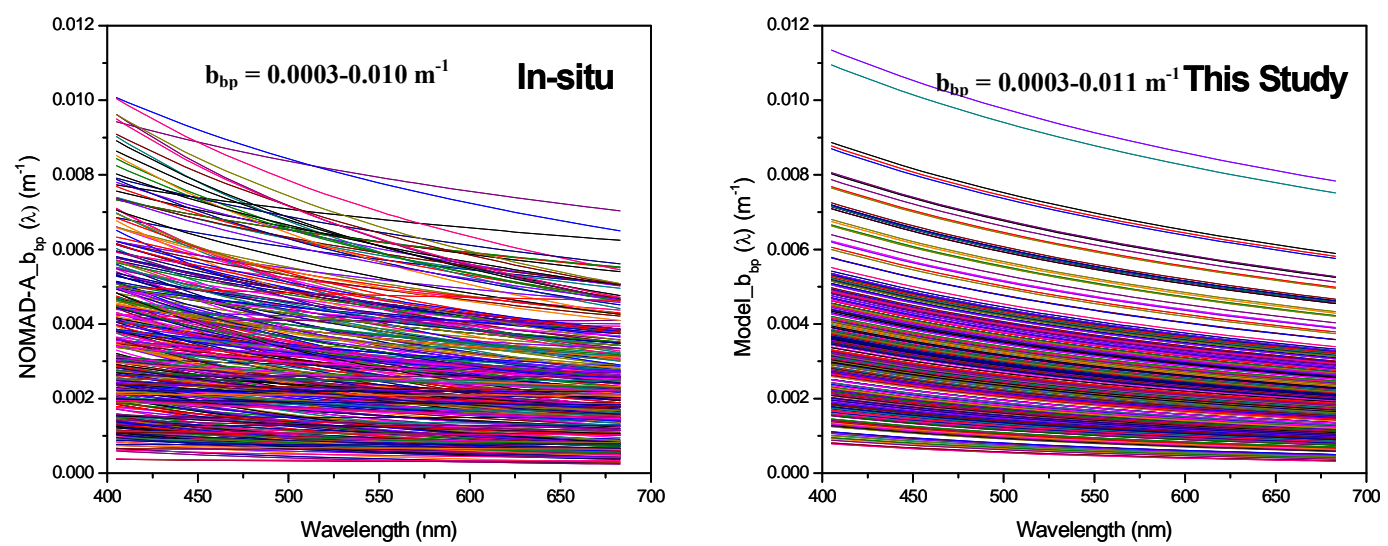

Fig. 4. Spectral variations in the particulate backscattering spectra $b_{\mathrm{bp}}(\lambda)\left(\mathrm{m}^{-1}\right)$ from the NOMAD-A in situ data (left panel) and new model (right panel).

wavelengths. The difference between modelled and in situ spectra is small and confined to a few observations made in particle-loaded waters. Such a small deviation of the model results may arise from the inadequate range of the slope coefficients to account for different compositions of the particulate materials. The difference may also be caused by the bottom influence and/or sea state conditions.

Earlier studies have reported that the $b_{\text {bp }}$ values vary from 0.0002 to $0.001 \mathrm{~m}^{-1}$ in clear oligotrophic waters (Antoine et al., 2011; Loisel et al., 2011), and from 0.03 up to $0.3 \mathrm{~m}^{-1}$ in turbid waters (Neukermans et al., 2011; Boss et al., 2009). The present model has the potential to estimate the $b_{\mathrm{bp}}$ values in oceanic waters, where these values vary from 0.0003 to $0.011 \mathrm{~m}^{-1}$ (Figs. 4 and 7).

\subsection{Model validation}

Figure 5 shows the scatter plots of the model-derived $b_{\mathrm{bp}}(\lambda)$ values versus in situ $b_{\mathrm{bp}}(\lambda)$ values at the key wavelengths (including red wavelengths) and the corresponding statistical evaluation results are summarised in Table 1 . Note that the $b_{\text {bp }}(\lambda)^{\text {insitu }}$ and $b_{\text {bp }}(\lambda)^{\text {model }}$ coefficients are highly correlated (close to the $1: 1$ line) indicating that the agreement between them is very good at 412, 443, 490, 510, 530, 555, 670, and $683 \mathrm{~nm}$ with small statistical errors (note that other inversion models do not provide $b_{\mathrm{bp}}(\lambda)$ values at the red wavelengths). These results reveal that $b_{\mathrm{bp}}(\lambda)$ values predicted by the new model at these wavelengths match with their corresponding in situ $b_{\mathrm{bp}}(\lambda)$ values well. Figure 6 provides a better clarity in the variations of RMSE and MRE (\%) of the new model at different wavelengths (412-683). The percentile MRE values are very small for the NOMAD-A data set, with the maximum value at $412 \mathrm{~nm}(\sim 0.45 \%)$ and the minimum value at $683 \mathrm{~nm}(\sim-0.33 \%)$. The model yields relatively high RMSE at $412 \mathrm{~nm}$ and low RMSE at 530 and $555 \mathrm{~nm}$. Overall (average), the model gives excellent statis- tics for the NOMAD-A data set $(\mathrm{RMSE} \sim 0.141$ and MRE $\sim 0.094 \%$ ).

\subsection{Inter-comparison with other inversion models}

In order to inter-compare the results of new model with those of the existing inversion models (Garver-Siegel-Maritorena model - GSM, quasi-analytical algorithm - QAA, and constrained linear matrix inversion model - CLM), all four models were applied to the independent NOMAD-B (NOMAD SeaWiFS match ups) and NOMAD-C (OOXIX IOP Algorithm Workshop data) data sets. Figure 7 shows that the $b_{\text {bp }}(\lambda)$ spectra (shape and magnitude) derived from the new models are similar to the in situ $b_{\mathrm{bp}}(\lambda)$ spectra, although showing slight differences with in situ $b_{\text {bp }}$ at the selected wavelengths. By contrast, other inversion models tend to distort the spectral shape and magnitude of $b_{\mathrm{bp}}(\lambda)$ to a noticeable extent. GSM model produces increasingly high $b_{\mathrm{bp}}$ values at the green wavelengths compared to the other two models. Overall, the new model provides more accurate $b_{\mathrm{bp}}$ $(\lambda)$ values in oceanic waters, therefore enabling us to extend it for application to the ocean colour remote-sensing applications.

Figure 8 shows the comparison of model-predicted $b_{\mathrm{bp}}$ ( $\lambda$ ) values versus in situ values (NOMAD-B) for the selected wavelengths $(412,443,490,510$ and $555 \mathrm{~nm})$. Table 2 presents the results of statistical analysis for all the models. It is observed that $b_{\mathrm{bp}}(\lambda)$ values derived from the QAA and GSM models are fairly linearly correlated with the in situ $b_{\mathrm{bp}}$ $(\lambda)$ values at all five wavelengths, although producing significant underestimations or overestimations across the range of $b_{\text {bp }}(\lambda)$ values at these wavelengths. On the contrary, $b_{\mathrm{bp}}(\lambda)$ values are significantly underestimated by the LM model (at the lower end of $b_{\mathrm{bp}}$ at these wavelengths) for this data set. As a result, the errors associated with this model are very high compared to those with the GSM and QAA models (Table 2). However, the LM model performs fairly well at higher $b_{\mathrm{bp}}$ 

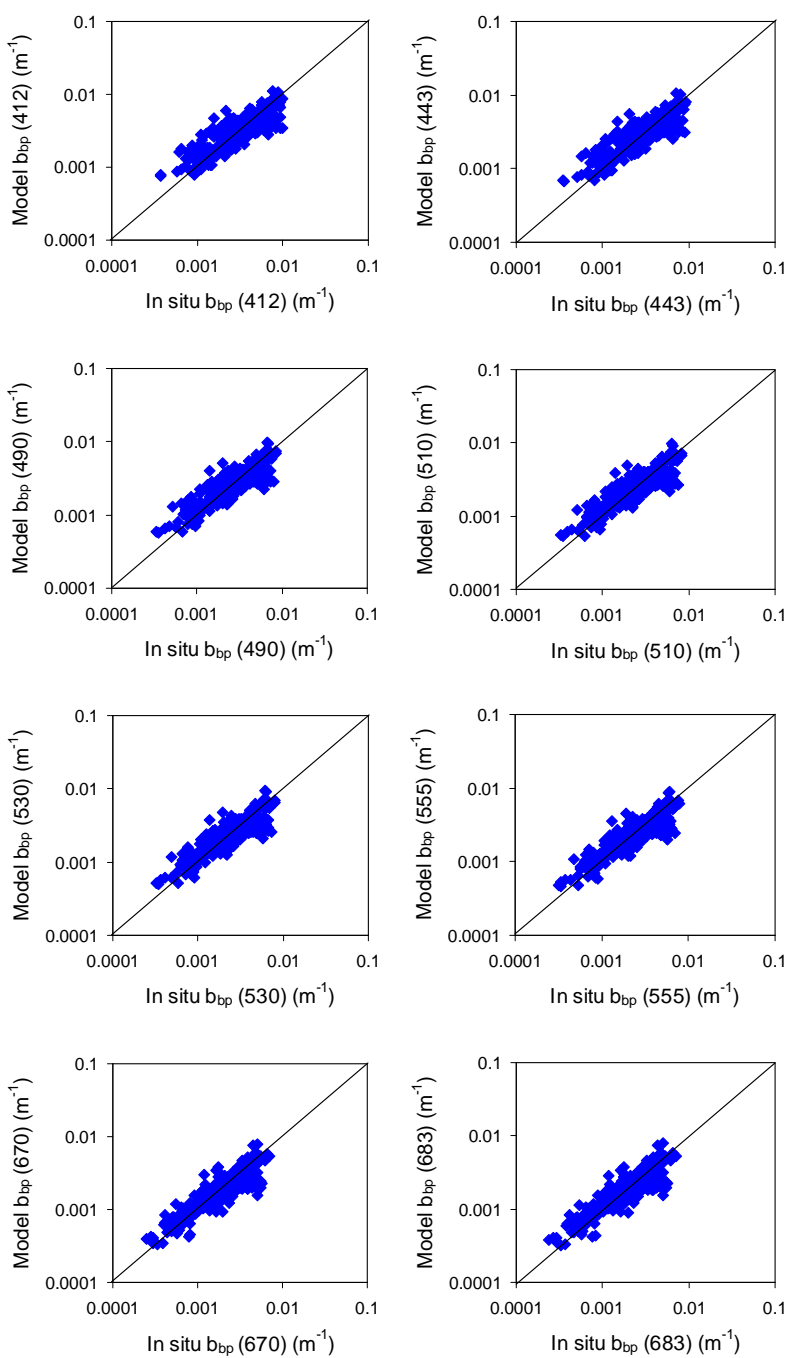

Fig. 5. Comparison between the in situ $b_{\mathrm{bp}}$ (NOMAD-A) and model $b_{\mathrm{bp}}\left(\mathrm{m}^{-1}\right)$ at $412,443,490,510,530,555,670$, and $683 \mathrm{~nm}$ $(N=331)$.

$(\lambda)$ values (coastal waters). It was also noticed that the LM model produced abnormally/erroneously high $b_{\mathrm{bp}}(\lambda)$ values (i.e. $b_{\mathrm{bp}} 10 \mathrm{~m}^{-1}$ at $412-555 \mathrm{~nm}$ for the SeaWiFS match up data, $N=51\left(b_{\mathrm{bp}} 10 \mathrm{~m}^{-1}\right)$ out of $N=125$ valid data). These satellite match-up data provided insight into the model performance at the key wavelengths. When the new model was applied to the same data sets, it can be seen that the $b_{\mathrm{bp}}(\lambda)$ values are more realistic (aligned more closely to the $1: 1$ line) without much overestimation and underestimation. This indicates relatively good agreement between the modelled $b_{\mathrm{bp}}(\lambda)$ and in situ $b_{\mathrm{bp}}(\lambda)$ values at $412,443,490,510$, and $555 \mathrm{~nm}$. The statistical evaluation results also show that the overall performance of the new model is good at the five SeaWiFS wavebands.

Further validation with the NOMAD-C (OOXIX IOP Algorithm Workshop) data set was performed to assess the ef- ficiency of these models. The results of this validation are shown in Fig. 9 and Table 3, where similar trends in $b_{\mathrm{bp}}$ $(\lambda)$ retrievals are observed with the other inversion models despite their errors being considerably low for this data set (except QAA model which caused more scattering of data between predicted and in situ $b_{\mathrm{bp}}(\lambda)$ with the increased errors). By contrast, the new model outperforms these inversion models in terms of producing accurate $b_{\mathrm{bp}}(\lambda)$ values (close agreement with in situ $b_{\mathrm{bp}}(\lambda)$ values as indicated by the data around the $1: 1$ line) at 412, 443, 490, 510, and $555 \mathrm{~nm}$ with low statistical errors (Table 3 ). These results confirm the potential of the new model to produce $b_{\mathrm{bp}}(\lambda)$ values in a wide range of waters.

To further investigate the performance of this new model, it was applied to the IOCCG simulated data set, which is representative of a wide range of waters (from clear to turbid). Figure 10 shows the comparisons of $b_{\mathrm{bp}}(\lambda)$ values derived from the new model with the IOCCG simulated data. It is observed that there is a slight underestimation between the modelled and in situ $b_{\text {bp }}(\lambda)$, but with good correlation coefficient $(0.82-0.87)$ and slope $(0.76-0.81)$ for the selected wavelengths (410-670 nm). The RMSE and MRE (\%) ranged from 0.388 to 0.417 and 14.25 to $15.28 \%$, respectively (Table 4). The results of the new model are notably stable across the wavelengths.

\section{Discussion and conclusion}

The importance of the particulate backscattering coefficients in ocean colour remote sensing has been discussed and emphasized in the previous studies (Hoge et al., 1996; Loisel and Stramski, 2000; Maritorena et al., 2002; Lee et al., 2002; Boss and Roesler, Wang et al., 2005; 2006; Smyth et al., 2006; Pinkerton et al., 2006; Gordon et al., 2009; Antoine et al., 2011; Shanmugam et al., 2011). Though several models are available to retrieve $b_{\mathrm{bp}}(\lambda)$, as the function of chlorophyll concentration or spectral remote-sensing reflectance, there is a lack of models to provide accurate estimates of $b_{\mathrm{bp}}(\lambda)$ over the entire visible wavelengths with any ocean colour sensors such as SeaWiFS, MODIS and MERIS. Furthermore, none of these models provide accurate $b_{\mathrm{bp}}(\lambda)$ values, even in the blue-green wavelengths in turbid coastal waters (Shanmugam et al., 2011). This is indeed due to improper parameterizations and inadequate $b_{\mathrm{bp}}(\lambda)$ measurements in a variety of waters covering a large geographical extent. As a consequence, very little information is available on the $b_{\mathrm{bp}}$ spectral variability (shape and magnitude). One of the differences with other inversion models is the input parameter. The new model makes use of $K_{\mathrm{d}}(490)$ as an input parameter which can be easily estimated from satellite ocean colour measurements. The non-linear least-square approach that does not require any assumption on the spectral shapes of absorption, scattering, and backscattering is identified as one of the best methods to accurately predict the $b_{\mathrm{bp}}(\lambda)$ spectral variability 

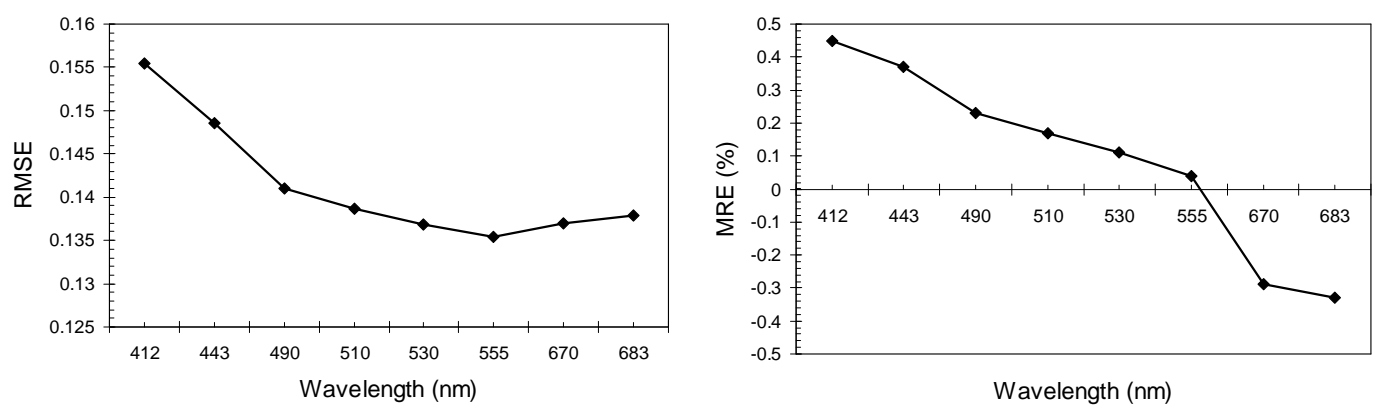

Fig. 6. RMSE and MRE $(\%)$ between the derived and NOMAD-A in situ data $(N=331)$ of the particulate backscattering coefficient $\left(b_{\mathrm{bp}}\right)$ $\left(\mathrm{m}^{-1}\right)$ for the new model.

Table 4. Statistical comparisons between the modelled and known particulate backscattering (IOCCG Simulated data). RMSE, MRE, BIAS and linear-regression results for the SeaWiFS bands centred at 410, 440, 490, 510, 530, 555, and $670 \mathrm{~nm}$.

\begin{tabular}{lrrrrrrr}
\hline \multicolumn{7}{c}{ IOCCG Simulated Data Set } \\
\hline IOP & RMSE & MRE (\%) & BIAS & Slope & Intercept & $R^{2}$ & N \\
\hline$b_{\text {bp }}(412)$ & 0.388 & 14.250 & 0.271 & 0.76 & -0.26 & 0.82 & 500 \\
$b_{\text {bp }}(443)$ & 0.389 & 14.040 & 0.271 & 0.77 & -0.24 & 0.82 & 500 \\
$b_{\text {bp }}(490)$ & 0.397 & 14.640 & 0.286 & 0.78 & -0.20 & 0.84 & 500 \\
$b_{\text {bp }}(510)$ & 0.401 & 14.980 & 0.294 & 0.79 & -0.19 & 0.85 & 500 \\
$b_{\text {bp }}(530)$ & 0.405 & 15.220 & 0.300 & 0.79 & -0.18 & 0.85 & 500 \\
$b_{\text {bp }}(555)$ & 0.409 & 15.430 & 0.306 & 0.80 & -0.16 & 0.86 & 500 \\
$b_{\text {bp }}(670)$ & 0.417 & 15.280 & 0.313 & 0.81 & -0.13 & 0.87 & 500 \\
Average & 0.401 & 14.834 & 0.292 & 0.78 & -0.20 & 0.84 & 500 \\
\hline
\end{tabular}

from the estimated $K_{\mathrm{d}}(490)$. A set of equations that relate AOPs to IOPs is derived and tested using independent in situ data and SeaWiFS satellite match-up data. In this study, $K_{\mathrm{d}}(490)$ is found to be an appropriate proxy to predict the $b_{\mathrm{bp}}(\lambda)$, which increases the accuracy of $b_{\mathrm{bp}}(\lambda)$ predictions with the new model in oceanic waters.

The inter-comparison results based on the above independent data sets are interesting that the new model provide the statistically improved $b_{\mathrm{bp}}(\lambda)$ values (at selected wavelengths) compared to other inversion models (GSM, QAA and LM). Among these three inversion models, GSM and QAA models give $b_{\mathrm{bp}}(\lambda)$ values better consistent with in situ data, while LM model shows poor performance at the selected wavelengths. Nevertheless, the new model outperforms these inversion models in terms of providing accurate $b_{\mathrm{bp}}(\lambda)$ values over the visible wavelength domain (400$700 \mathrm{~nm}$ ), and thus it has wide applicability in oceanic coastal waters.

An underestimation of the new model for the IOCCG simulated data is due to the fact that the model parameterizations do not include much data from turbid coastal waters. It can be further improved by incorporating more in situ measurements from such waters.

The present study is expected to form the basis for robust relationships between $b_{\mathrm{bp}}(\lambda)$ and $K_{\mathrm{d}}(490)$ in a wide range of oceanic waters. In this paper, we discussed how the diffuse attenuation coefficient is significantly correlated with the spectral particulate backscattering coefficient. The relationship between $b_{\mathrm{bp}}$ and $K_{\mathrm{d}}(490)$ is derived, exploiting the fact that the inverse spectral dependency exists for particulate backscattering coefficient $\left(b_{\mathrm{bp}}\right)$ (i.e. $b_{\mathrm{bp}}(\lambda) \propto \lambda^{-Y}$ ).

In such a case, the optical variability in the geometric structure of the underwater light field is governed by the relative intensity of " $b_{\mathrm{bp}}$ ", whereby leading to the formation of isotropic region. The diffused field thus formed becomes less dependent on illumination geometry and solar zenith angle at the blue wavelengths (Zheng et al., 2002). The dominant effect of scattering over absorption process at $K_{\mathrm{d}}(490)$ relates a very weak dependency of solar zenith angle and absorption on $K_{\mathrm{d}}(490)$. Therefore, it is of prime importance to study the change in apparent optical parameter $K_{\mathrm{d}}(490)$ and the spatial effect induced due to particulate backscattering $\left(b_{\mathrm{bp}}\right)$ to the geometric structure of the underwater light field, in proper correlation.

Zheng et al. (2002) discussed that a weak dependency of $K_{\mathrm{d}}$ at blue wavelengths based on early experimental (e.g. Hojerslev et al. (1974) in clear water off Sardinia, Nelson and Aas (1977) in turbid Oslofjord waters, and Baker and Smith (1979) in San Vicente Reservoir near San Diego) and model results reported by different researchers, indicated that 

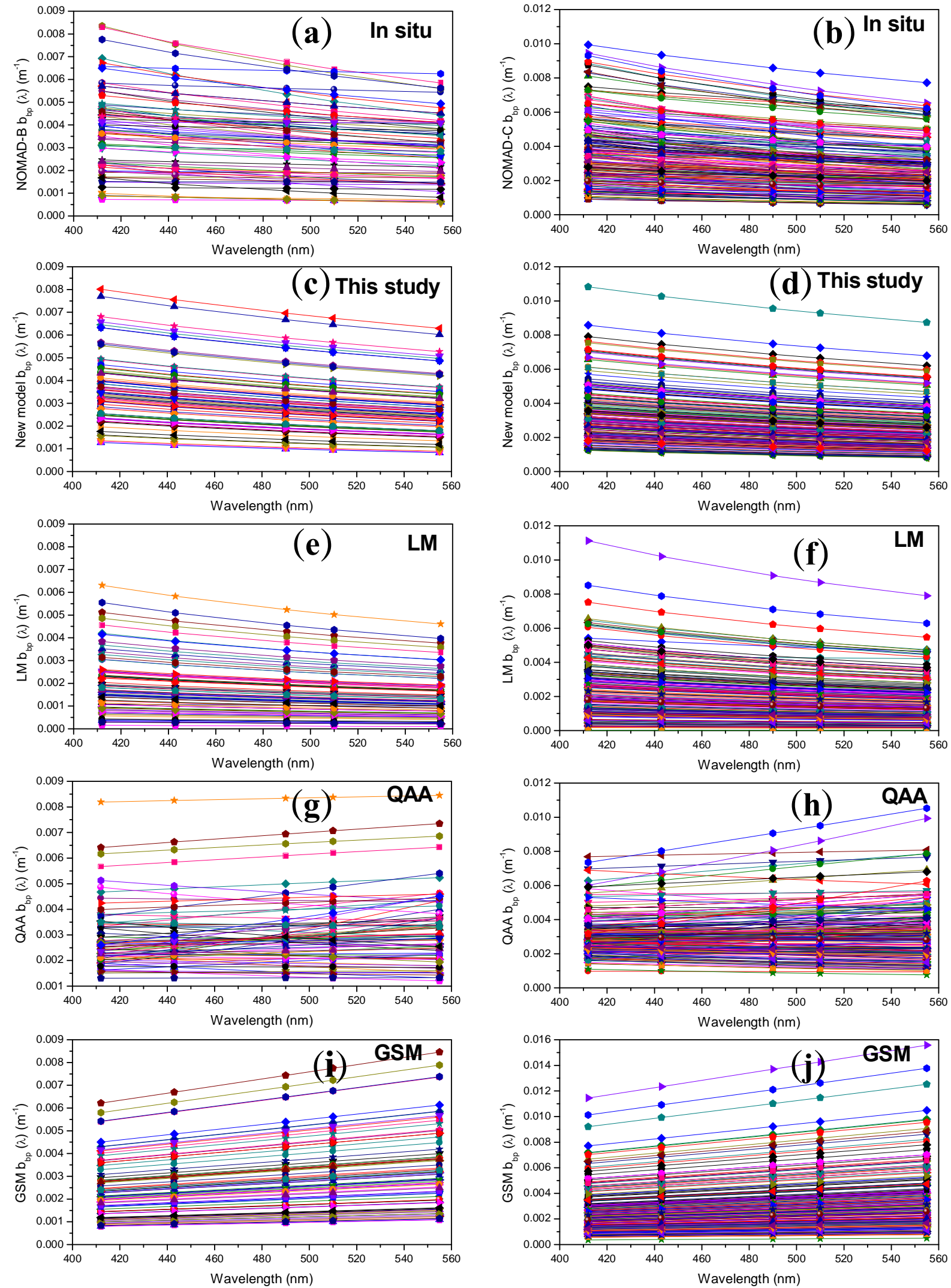

Fig. 7. Spectral variations in the particulate backscattering spectra $b_{\mathrm{bp}}(\lambda)\left(\mathrm{m}^{-1}\right)$ from the NOMAD-B data (left panel) and NOMAD-C (right panel) data (a and $\mathbf{b})$ and from the four inversion models $(\mathbf{c}-\mathbf{j})$. 

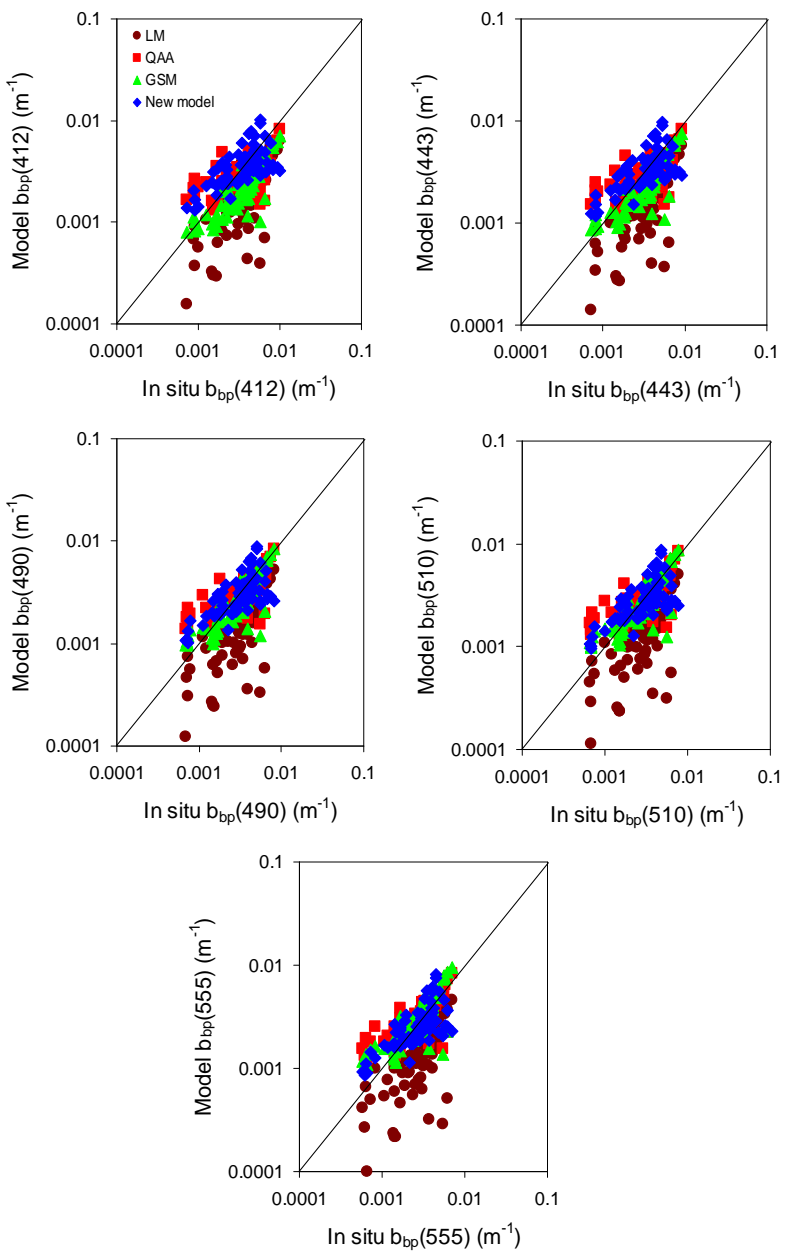

Fig. 8. Comparisons between the model $b_{\mathrm{bp}}(\lambda)\left(\mathrm{m}^{-1}\right)$ (from NOMAD SeaWiFS $R_{\mathrm{rs}}$ match-up data set) and NOMAD-B in situ data at the wavelengths from 412 to $555 \mathrm{~nm}(N=74)$.

the effect of solar elevation on $K_{\mathrm{d}}$ is relatively small. It is also studied that at shorter wavelengths, $K_{\mathrm{d}}$ has been considered to be independent of solar zenith angle. However, more recent experimental results based on the time-series data collected with moored instruments in the upper layer of the Sargasso Sea showed a significant correlation between $K_{\mathrm{d}}$ and solar zenith angle, especially at the red wavelengths (Stramska and Frye, 1997).

The offset values are considered constants in the present study because there is weak dependency of model on solar zenith angle and absorption and only the scattering effect is dominant on $K_{\mathrm{d}}$ at $490 \mathrm{~nm}$. Since the formulation is based on only $K_{\mathrm{d}}$ at $490 \mathrm{~nm}$ which means that this spectral domain is dominated by scattering effect rather than other effects, there is good correlation between $K_{\mathrm{d}}(490)$ and $b_{\mathrm{bp}}(530)$ and $b_{\mathrm{bp}}(555)$ (Fig. 2). The new model has flexibility to use input as a true measured $K_{\mathrm{d}}(490)$ or $K_{\mathrm{d}}(490)$ computed from remote-sensing reflectance-based algorithms. It should be noted that accurate values of $K_{\mathrm{d}}(490)$ are necessary to cor-
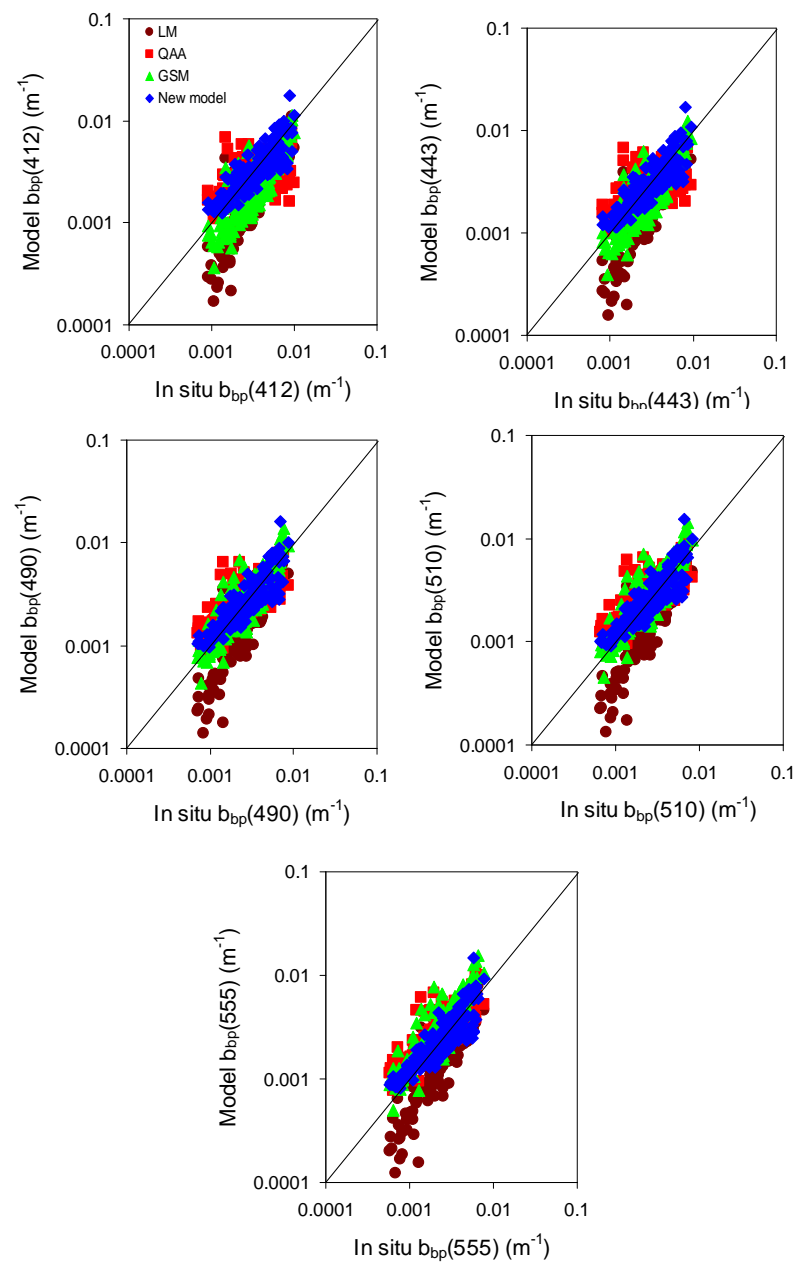

Fig. 9. Comparisons between the model $b_{\mathrm{bp}}(\lambda)\left(\mathrm{m}^{-1}\right)$ and NOMAD-C in situ data at the wavelengths from 412 to $555 \mathrm{~nm}$ $(N=185)$.

rectly estimate the particulate backscattering $\left(\mathrm{b}_{b p}\right)$ using the new approach.

Thus, comprehensive and consistent in situ measurements of these optical properties in typical coastal waters will allow the refinement of the new model which can be used to derive information on the refractive index and particle size distribution based on certain optical models to study particle populations and their characteristics in coastal waters. The results discussed in this paper will have important implications for ocean colour remote sensing. 

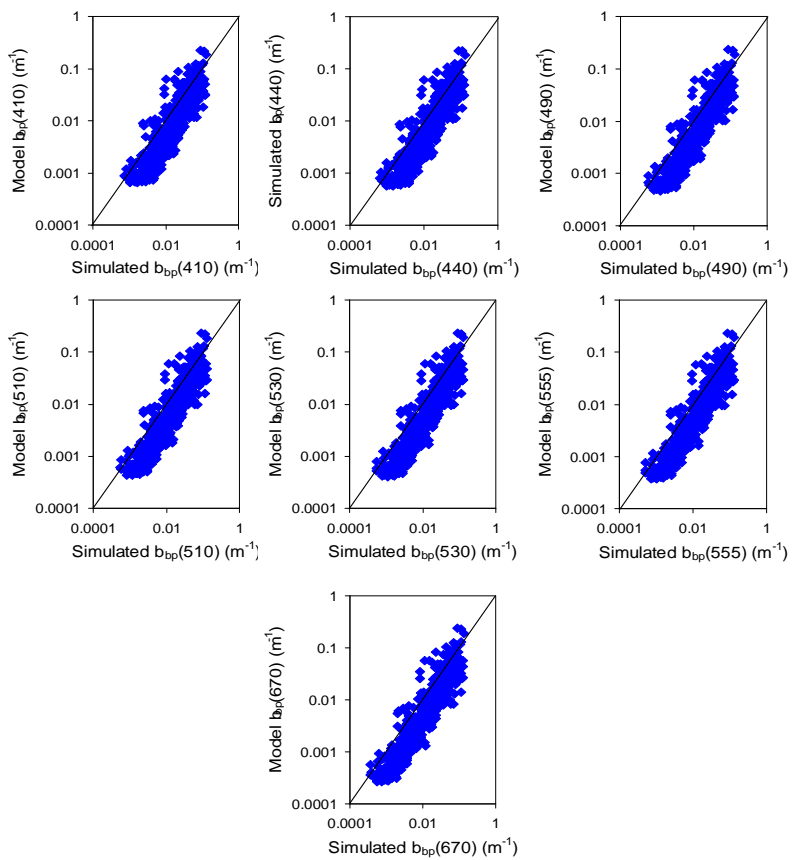

Fig. 10. Comparisons between the model $b_{\mathrm{bp}}(\lambda)\left(\mathrm{m}^{-1}\right)$ and IOCCG simulated data at the wavelengths from 410 to $670 \mathrm{~nm}(N=500)$.

Acknowledgements. This work was supported by grants from the NRB (project number OEC1112106NRBXPSHA). This work was also supported in part by the MHRD, Government of India and Indian Institute of Technology Madras. The authors would like to thank the NASA Ocean Biology Processing Group for making available the global, high-quality bio-optical (NOMAD) data set to this study. We are grateful to the reviewers for the valuable comments, which helped to improve the structure and content of this paper.

Edited by: R. Sabia

\section{References}

Antoine, D., Siegal, D. A., Kostadinov, T., Maritorena, S., Nelson, N. B., Gentilli, B., Vellucci, V., and Guillocheau, N.:Variability in optical particle backscattering in contrasting bio-optical oceanic regimes, Limnol. Oceanogr., 56, 955-973, 2011.

Babin, M., Morel, A., Fournier-Sicre, V., Fell, F., and Stramski, D.: Light scattering properties of marine particles in coastal and oceanic waters as related to the particle mass concentration, Limnol. Oceanogr., 48, 843-859, 2003b.

Baker, K. S. and Smith, R. C.: Quasi-inherent characteristics of the diffuse attenuation coefficient for irradiance, in Ocean Optics VI, edited by: Duntley, S. Q., Proc. SPIE 208, 60-63, 1979.

Bohren, C. F. and Singham, S. B.: Backscattering by Nonspherical Particles: A Review of Methods and Suggested New Approaches, J. Geophys. Res., 96, 5269-5277, 1991.

Boss, E. and Roesler, C.: Over constrained linear matrix inversion with statistical selection, Z. Lee Ed., Remote Sensing of Inherent Optical Properties: Fundamentals, Tests of Algorithms, and
Applications, IOCCG, Dartmouth, NS, Canada, IOCCG Rep. 5, 2006.

Boss, E., Taylor, L., Gilbert, S., Gundersen, K., Hawley, N., Janzen, C., Johengen,T., Purcell, H., Robertson, C., Schar, D. W. H., Smith, G. J., and Tamburri, M. N.: Comparison of inherent optical properties as a surrogate for particulate matter concentration in coastal waters, Limnol. Oceanogr., 7, 803-810, 2009.

Brewin, R. J. W., Devred, E., Sathyendranath, S., Lavender, S. J., and Hardman-Mountford, N. J.: Model of phytoplankton absorption based on three size classes, Appl. Opt., 50, 4535-4549, 2011.

Bricaud, A. and Morel, A.: Light attenuation and scattering by a phytoplanktonic cells: A theoretical modeling, Appl. Opt., 25, 571-580, 1986.

Carder, K. L., Chen, F. R., Lee, Z. P., Hawes, S. K., and Kamykowski, D.: Semianalytic Moderate-Resolution Imaging Spectrometer algorithms for chlorophyll-a and absorption with bio-optical domains based on nitrate depletion temperatures, J. Geophys. Res., 104, 5403-5421, 1999.

Chami, M., Shybanov, E. B., Khomenko, G. A., Lee, M. E. G., Martynov, O. V., and Korotaev, G. K.: Spectral variation of the volume scattering function measured over the full range of scattering angles in a coastal environment, Appl. Opt., 45, 3605-3619, 2006.

Clavano, W. R., Boss, E., and Karp-Boss, L.: Inherent Optical Properties of Non-Spherical Marine-Like Particles - From Theory to Observations, Oceanogr. Mar. Biol., 45, 1-38, 2007.

Coleman, T. F. and Li, Y.: An Interior, Trust Region Approach for Nonlinear Minimization Subject to Bounds, SIAM J. Optimization, 6, 418-445, 1996.

Dall'Olmo, G., Westberry, T. K., Behrenfeld, M. J., Boss, E., and Slade, W. H.: Significant contribution of large particles to optical backscattering in the open ocean, Biogeosciences, 6, 947-967, doi:10.5194/bg-6-947-2009, 2009.

Garver, S. A. and Siegel, D.: Inherent optical property inversion of ocean colour spectra and its biogeochemical interpretation 1. Time series from the Sargasso Sea, J. Geophys. Res., 102, 18607-18625, 1997.

Gordon, H. R.: Spectral variations in the volume scattering function at large angles in natural waters, J. Opt. Soc. America, 64, 773$775,1974$.

Gordon, H. R.: A semi-analytic radiance model of ocean colour, J. Geophys. Res., 93, 10909-10924, 1988.

Gordon, H. R., Brown, O. B., and Jacobs, M. M.: Computed relationships between the inherent and apparent optical properties of a flat homogeneous ocean, Appl. Opt., 14, 2417-2427, 1975.

Gordon, H. R., Dependence of the diffuse reflectance of natural waters on the sun angle, Limnol. Oceanogr., 34, 1389-1409, 1989.

Gordon, H. R., Lewis, M. R., McLean, S. D., Twardowski, M. S., Freeman, S. A., Voss, K. J., and Boynton, G. C.: Spectra of particulate backscattering in natural waters, Optics Expr., 17, 16 192-16 208, 2009.

Green, R. E., Sosik, H. M., Olson, R. J., and DuRand, M. D.: Flow cytometric determination of size and complex refractive index for marine particles: Comparison with independent and bulk estimates, Appl. Opt., 42, 526-541, 2003.

Hoge, F. E. and Lyon, P. E.: Satellite retrieval of inherent optical properties by linear matrix inversion of oceanic radiance mod- 
els: An analysis of model and radiance measurement errors, J. Geophys. Res.-Oc., 101, 16631-16648, 1996.

Hojerslev, N. K.: Daylight measurements for photosynthetic studies in the Western Mediterranean, University of Copenhagen Institute of Physical Oceanography Report, 26, 1974.

Jerlov, N. G.: Marine Optics, Elsevier, Amsterdam, 1976.

Kirk, J. T. O.: A Monte Carlo study of the nature of the underwater light field in, and the relationships between optical properties of, turbid yellow waters, Austr. J. Mar. Freshwater Res., 32, 517532, 1981.

Kirk, J. T. O.: Dependence of relationship between inherent and apparent optical properties of water on solar altitude, Limnol. Oceanogr., 29, 350-356, 1984.

Kirk, J. T. O.: Volume scattering function, average cosines, and the underwater light field, Limnol. Oceanogr., 36, 455-467. 1991.

Kitchen, J. C. and Zaneveld, J. R. V.: A three-layered sphere model of the optical properties of phytoplankton, Limnol. Oceanogr., 37, 1680-1690, 1992.

Kostadinov, T. S., Siegel, D. A., and Maritorena, S.: Retrieval of the particle size distribution from satellite ocean color observations, J. Geophys. Res., 114, C09015, doi:10.1029/2009JC005303, 2009.

Lee, Z. P.: Remote Sensing of Inherent Optical Properties: Fundamentals, Tests of Algorithms, and Applications, IOCCG, Dartmouth, NS, Canada, IOCCG Report 5, 2006.

Lee, Z. P., Carder, K. L., and Arnone, R. A.: Deriving inherent optical properties from water colour: a multiband quasi-analytical algorithm for optically deep waters, Appl. Opt., 41, 5755-5772, 2002.

Lee, Z. P., Du, K. P., and Arnone, R.: A model for the diffuse attenuation coefficient of downwelling irradiance, J. Geophys. Res., 110, C02016, doi:10.1029/2004JC002275, 2005a.

Lee, Z. P., Darecki, M., Carder, K. L., Devis, C. O., Stramski, D., and Rhea, W. J.: Diffuse attenuation coefficient of downwelling irradiance: An evaluation of remote sensing methods, J. Geophys. Res., 110, C02017, doi:10.1029/2004JC002573, 2005 b.

Lewis, M. R., Carr, M., Feldman, G., Esaias, W., and McMclain, C.: Influence of penetrating solar radiation on the heat budget of the equatorial pacific ocean, Nature, 347, 543-545, 1990.

Loisel, H. and Stramski, D.: Estimation of the inherent optical properties of natural waters from the irradiance attenuation coefficient and reflectance in the presence of Raman scattering, Appl. Opt., 39, 3001-3011, 2000.

Loisel, H., Nicolas, J. M., Sciandra, A., Stramski, D., and Poteau, A.: Spectral dependency of optical backscattering by marine particles from satellite remote sensing of the global ocean, J. Geophys. Res. (1978-2012), 111, C09015, doi:10.1029/2005JC003367, 2006.

Loisel, H., Vantrepotte, V. Norkvist, K., Mériaux, X., Kheireddine, M., Ras, J., Pujo-Pay, M., Combet, Y.,Leblanc, K., Dall'Olmo, G. Mauriac, R. Dessailly, D., and Moutin, T.: Characterization of the bio-optical anomaly and diurnal variability of articulate matter, as seen from scattering and backscattering coefficients, in ultraoligotrophic eddies of the Mediterranean Sea, Biogeosciences, 8 , 3295-3317, doi:10.5194/bg-8-3295-2011, 2011.

Maritorena, S., Siegel, D. A., and Peterson, A. R.: Optimization of a semianalytical ocean colour model for global-scale applications, Appl. Opt., 41, 2705-714, 2002.
Mobely, C. D.: Light and water, Radiative transfer in natural waters, San Diego, Academic Press, 1994.

Mobely, C. D.: The Optical Properties of Water, in: Handbook of Optics, Fundamental, Techniques, and Design, edietd by: Bass, M., Van Stryland, E. W., Williams, D. R., and Wolf, W. L., New York, McgGraw-Hill, vol. I, pp. 43.3-43.56, 1995.

Morel, A.: Diffusion de la lumie 're par les eaux de mer: Re'sultats experimentaux et approach the'oretique, in AGARD Lecture Series, 3.1.1-3.1.76, 1973.

Morel, A. and Ahn, Y. H.: Optics of heterotrophic nanoflagellates and ciliates. A tentative assessment of their scattering role in oceanic waters compared to those of bacterial and algal cells, J. Mar. Res., 49, 177-202, 1991.

Morel, A. and Antoine, D.: Heating rate within the upper ocean in relation to its bio-optical state, J. Phys. Oceanogr., 24, 16521665, 1994.

Morel, A. and Loisel H.: Apparent optical properties of oceanic water: Dependence on the molecular scattering contribution, Appl. Opt., 37, 4765-4776, 1998.

Mueller, J. L.: SeaWiFS algorithm for the diffuse attenuation coefficient, K (490), using water-leaving radiances at 490 and $555 \mathrm{~nm}$, in: SeaWiFS Postlaunch Calibration and Validation Analyses, part 3, edited by: Hooker, S. B., NASA Goddard Space Flight Cent., Greenbelt, Md., 24-27, 2000.

NASA, 2009. Diffuse attenuation coefficient $\left(K_{\mathrm{d}}\right)$ for downwelling irradiance at $490 \mathrm{~nm}$. NASA Ocean Biology Processing Group, available at: http://oceancolour.gsfc.nasa.gov/REPROCESSING/ R2009/kdv4/ (last access: 2 July 2009), 2009.

Nielsen, J. H. and Aas, E.: Relation between solar elevation and the vertical attenuation coefficient of irradiance in Oslofjorden, University of Oslo Report, 31 pp., 1977.

Neukermans, G., Loisel, H., Mériaux, X., Astoreca, R. and McKee, D.: In situ variability of mass-specific beam attenuation and backscattering of marine particles with respect to particle size, density, and composition, Limnol. Oceanogr., 57, 24-144, 2012.

Pinkerton, M. H., Moore, G. F., Lavender, S. J., Gall, M. P., Oubelkheir, K., Richardson, K. M., Boyd, P. W., and Aiken, J.: A method for estimating inherent optical properties of New Zealand continental shelf waters from satellite ocean colour measurements, New Zealand J. Mar. Freshwater Res., 40, 227-247, 2006.

Platt, T.: Primary production of ocean water column as a function of surface light intensity: Algorithms for remote sensing, Deep-Sea Res., 33, 149-163, 1986.

Preinsendorper, R. W.: Application of radiative transfer theory to light measurements in the sea, Monogr. Int. Union Geod. Geophys, Paris, 10, 11-30, 1961.

Preisendorfer, R. W.: Hydrologic Optics, vol. 1, Introduction, Natl. Tech. Inf. Serv., Springfield, Va, 1976.

Risovic, D.: Effect of suspended particulate-size distribution on the backscattering ratio in the remote sensing of seawater, Appl. Opt., 41, 7092-7101, 2002.

Roesler, C. S. and Boss, E.: Spectral beam attenuation coefficient retrieved from ocean colour inversion, Geophys. Res. Lett., 30, 1468, doi:10.1029/2002GL016185, 2003.

Sathyendranath, S. and Platt, T.: The spectral irradiance field at the surface and in the interior of the ocean: A model for applications in oceanography and remote sensing, J. Geophys. Res., 93, 92709280, 1988. 
Sathyendranath, S., Prieur, L., and Morel, A.: A three-component model of ocean colour and its application to remote sensing of phytoplankton pigments in coastal waters, Internat. J. Remote Sens., 10, 13731-1394, 1989.

Shanmugam, P., Sundarbalan, B., Ahn, Y. H., and Ryu, J. H.: A new inversion model to retrieve the particulate backscattering in coastal oceans, IEEE Trans. Geosci. Rem. Sens., 49, 2463-2475, 2011.

Smith, R. C. and Baker, K. S.: Optical properties of the clearest natural waters, Appl. Opt., 20, 177-184, 1981.

Smyth, T. J., Moore, G. F., Hirata, T., and Aiken, J.: Semianalytical model for the derivation of ocean colour inherent optical properties: description, implementation, and performance assessment, Appl. Opt., 46, 429-430, 2006.

Stramski, D. and Kiefer, K. A.: Light scattering by microorganisms in the open sea, Prog. Oceanogr., 28, 4 343-4383, 1991.

Stramska, M. and Frye, D.: Dependence of apparent optical properties on solar altitude: experimental results based on mooring data collected in the Sargasso Sea, J. Geophys. Res., 102, 1567915691, 1997.

Stramski, D., Bricaud, A., and Morel, A.: Modeling the inherent optical properties of the ocean based on the detailed composition of planktonic community, Appl. Opt., 40, 2929-2945, 2001.

Stramski, D., Boss, E., Bogucki, D., and Voss, K. J.: The role of seawater constituents in light backscattering in the ocean, Prog. Oceanogr., 61, 27-56, 2004.

Sun, D., Li, Y., Wang, Q., Gao, J., Lv, H., Le, C., and Huang, C.: Light scattering properties and their relation to biogeochemical composition in a turbid productive lake: Lake Taihu case study, Appl. Opt., 48, 1979-1989, 2009.

Twardowski, M., Boss, E., Macdonald, J. B., Pegau, W. S., Barnard, A. H., and Zaneveld, V. J. R.: A model for estimating bulk refractive index from the optical backscattering ratio and the implications for understanding particle composition in case I and case II waters, J. Geophys. Res., 106, 14129-14142, 2001.
Twardowski, M. S., Lewis, M., Barnard, A., and Zaneveld, J. R. V.: In-water instrumentation and platforms for ocean color remote sensing applications, in: Remote Sensing of Coastal Aquatic Waters, edited by: Miller, R., Del Castillo, C., and McKee, B., Springer Publishing, Dordrecht, Netherlands, 69-100, 2005.

Twardowski, M. S., Claustre, H., Freeman, S. A., Stramski, D., and Huot, Y.: Optical backscattering properties of the "clearest" natural waters, Biogeosciences, 4, 1041-1058, doi:10.5194/bg4-1041-2007, 2007.

Van de Hulst, H. C.: Light Scattering by Small Particles, John Wiley, New York, 1957.

Van de Hulst H. C.: Light scattering by small particles, Dover Publications, 1981.

Victor, M. V., Land, P. E., Tilstone, G. H., Widdicombe, C., and Fishwick, J. R.: Particulate scattering and backscattering related to water constituents and seasonal changes in the Western English Channel, J. Plankt. Res., 32, 603-629, 2010.

Wang, P., Boss, E. S., and Roesler, C. S.: Uncertainties of inherent optical properties obtained from semianalytical inversions of ocean colour, Appl. Opt., 44, 4074-4085, 2005.

Werdell, P. J. and Bailey, S. W.: An improved in situ bio-optical data set for ocean colour algorithm development and satellite data product validation, Remote Sens. Environ., 98, 122-140, 2005.

Werdell, P. J., Bailey, S. W., Franz, B. A., Harding Jr., L. W., Feldman, G. C., and McClain, C. R.: Regional and seasonal variability of chlorophyll-a in Chesapeake Bay as observed by SeaWiFS and MODIS-Aqua, Remote Sens. Environ., 113, 1319-1330, 2009.

Zaneveld, J. R. V. and Kitchen, J. C.: The variation in the inherent optical properties of phytoplankton near an absorption peak as determined by various models of cell structure, J. Geophys. Res., 100, 13309-13320, 1995.

Zheng, X., Dickey, T., and Chang, G.: Variability of the downwelling diffuse attenuation coefficient with consideration of inelastic scattering, Appl. Opt., 41, 6477-6488, 2002. 